\title{
The effectiveness of non-invasive neuromuscular patients in KAMC
}

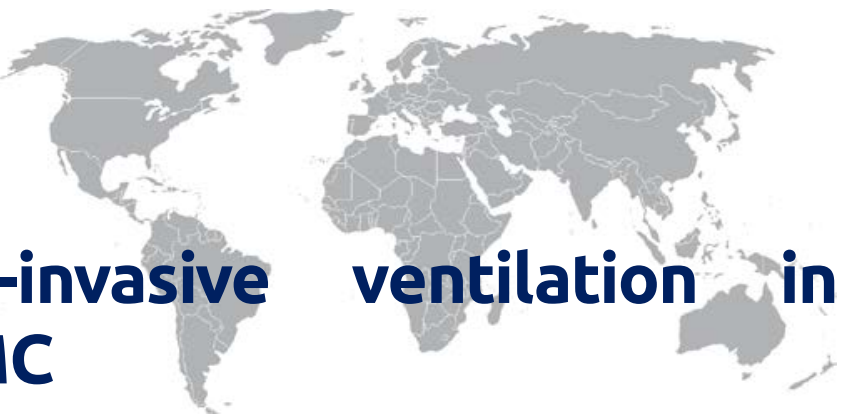

Farhan Al. Enezi1, Sreekanth Mohan1, Faisal Ahmed Alghamdi ${ }^{1}$, Turki Mohammed Alsabhan ${ }^{1}$, Mohammed Ibrahim Alshahrani', Abdulaziz Mohammed Alkhrisi', Saad Fhad Alsatame ${ }^{1}$, Shoeb Qureshi ${ }^{1}$

\begin{abstract}
Introduction: The impact of non-invasive ventilation on neuromuscular disease (NMD) has become evident over the past two decades due to frequent use of this technique. It allows some patients with non-progressive pathology to almost live a normal life. The purpose of this study is to indicate the impact of NIV and its results in NMD patients.

Objectives: The primary objectives for the study were to find the incidence and outcome of NMD patient on NIV, to determine whether NIV can avoid intubation and Mechanical ventilation and to compare vital signs and arterial blood gas parameters before and after NIV.

Methodology: This retrospective study was conducted during a period from January 2010 to October 2017 in King Abdul-Aziz Medical city (KAMC). The data was collected from Medical Record Department. The collected data got statistically analyzed and results obtained by using SPSS software. A total number of 21 patients admitted in KAMC in adult ICUs, wards, and Emergency room for both males and females with neuromuscular diseases with an age above 18 years old were included. Parameters related to patients and NIV were collected and recorded in an excel sheet and there by SPSS software.

Results: A total of 21 patients enrolled in this study. There were 14 males and 7 females. The minimum age 19 years old and the maximum 81 years old with a mean age of 45. Arterial Blood Gas done Pre and Post NIV and compared using paired't' test. The pre and post pH on NIV was significant with a $\mathrm{P}$ value (p: 0.029 ). The pre and post $\mathrm{PaCO} 2$ on NIV with a $\mathrm{P}$ value (P: 0.034$)$ and oxygenation in pre and post NIV with a P value (P: 0.008$)$ was also significant.

Conclusion: In this study, since most of the results indicates poor prognosis, it is difficult to say that NIV improve the quality of life. This can be due to the limitations and bias in the study like the heterogeneity of the diseases and bias can be due to the hospital and its policies.
\end{abstract}

Keywords: neuromuscular disease, NMD patient, Mechanical ventilation, non-progressive pathology, non-invasive ventilation

\section{INTRODUCTION}

Neuromuscular disease (NMD) is an interesting disorder that needs more investigation. Unlike other diseases, NMD does not affect a certain age. However, the patient's age plays a huge role in the effectiveness and benefit of the treatment. When the therapy was used with young patients the outcome was better. There are many methods that used in order to treat NMD. One of these method is noninvasive ventilation. The impact of noninvasive ventilation (NIV) in clinical practices on neuromuscular disease (NMD) has become prevalent over the past two decades \& is being vastly used all over.

\section{REVIEW OF LITERATURE}

The effect of noninvasive ventilation (NIV) in neuromuscular disease (NMD) has become evident over the past two decades $\&$ is being widely used all over. It helps to extend the survivability in certain diseases like muscular dystrophy, rapidly deteriorating disease like amyotrophic lateral sclerosis etc. without further reduction in mortality rate [1]. Many youngsters and children with NMD survive to adulthood by using noninvasive ventilation [2]. Since NMD accounts for about $1 \%$ of the world population; it is considered one of the rarest diseases in the world [3]. Neuromuscular diseases impact the nerves that control our voluntary muscles [4]. It affects the muscles either directly or indirectly through the

\footnotetext{
1 Respiratory Therapy Department, College Of Applied Medical Sciences, King Saud Bin Abdulaziz University For Health Sciences, Riyadh, Saudi Arabia

Correspondence: Farhan Al. Enezi

Respiratory Therapy Department, College Of Applied Medical Sciences, King Saud Bin Abdulaziz University For Health Sciences, Riyadh, Saudi Arabia

Received: 1 Apr 2018, Accepted: 7 Jun 2018

E-mail: farhanfarhanalenezi@gmail.com
}

(C) 2018 by the authors; licensee Modestum Ltd., UK. This article is an open access article distributed under the terms and conditions of the Creative Commons Attribution License (http://creativecommons.org/licenses/by/4.0/). 
central nervous system which can cause spasm and some degree of paralysis depending on the location and the origin of the problem. It can affect respiratory muscles which can contribute to respiratory failure $[4,5]$. On the other hand, non-invasive ventilation is a technique which adapts positive pressure to help respiration and to reduce endotracheal intubation. It mainly includes two modes which is continuous positive airway pressure (CPAP) and noninvasive pressure support ventilation (NIPSV) [6, 7]. NIPSV mode depends on a person's inspiration and expiration. In addition, NIPSV has an expiratory pressure called EPAP or PEEP and inspiratory pressure called IPAP, resulting in a bi-level pressure modality (BIPAP) which has shown a reduced intubation rate [8]. In NMD there is a mismatch between the muscular system and the neuronal system that lead to loss of muscle control which leads to muscle fatigue $\&$ there by difficulty in breathing [9]. This weakness in respiratory muscles make shallow breathing when lying or at the time of sleep \& can also lead to carbon dioxide retention [10]. Nocturnal hypoventilation is yet another problem associated with NMD which is characterized by nocturnal shallow breathing, hypercapnia \& hypoxemia which can lead to tiredness during daytime [11, 12]. NIV has proven its effectiveness in improving the breathing quality in NMD where the symptoms start from dyspnea and it could worsen until it causes death due to respiratory failure. It decreases the incidence of shallow breathing, decreasing the carbon dioxide and increasing the oxygen in the blood. $[13,14,16]$. Even though there are studies which shows its effectiveness, there are many other studies which shows that NIV cannot be used for patients who have acute neuromuscular disorders like Guillain-Barre syndrome (GBS). In these kind of diseases the upper airway gets affected more and NIV does not treat this area, but it could make it worse by increasing the probability of pulmonary aspiration [15]. Respiratory insufficiency occurs slowly and follows a predictable rate of worsening in patients with chronic, progressive neuromuscular diseases such as muscular dystrophies and amyotrophic lateral sclerosis (ALS) [17]. There are types of neuromuscular disorders with an acute or sub-acute onset, and some other types with sudden exacerbations, thus presenting with acute respiratory failure $[17,18]$. This respiratory failure in these patients may not be initially recognized because they do not have frank abnormalities on auscultation or severe cyanosis. But certain signs such as paradoxical abdominal movement, use of accessory respiratory muscles, or becoming breathless while talking should raise a warning [18]. An investigation for NMD such as vital capacity, mouth pressures, arterial blood gases, chest x-ray and sometimes overnight respiratory monitoring is important [19]. Studies have shown that long-term noninvasive ventilation improves symptoms, gas exchange, quality of life and survival [20]. Neuromuscular diseases are those diseases that cause prolonged ventilator dependency [21].

Since NMD though not very common but can lead to respiratory failure, morbidity, mortality \& can affect the quality of life as well, the purpose of this study is to find out the number of patients who got admitted with neuromuscular disorder who received noninvasive ventilation in King Abdul-Aziz medical City (KAMC). This study also emphasis the effectiveness of NIV \& the outcome of patients who had undergone treatment with NIV.

\section{MATERIALS AND METHODS}

We conducted our research based on the patients' files in King Abdul-Aziz Medical city, Medical Record Department. Then, we collected and analyzed the results using statistical methods. We conducted a retrospective study by using convenient sampling technique during a period from January 2010 to October 2017. We studied 21 patients of KAMC in adult ICUs, wards, and Emergency room for both males and females with neuromuscular diseases. Inclusion criteria included all adult Patients 18 years old and above. Exclusion criteria included all patients less than 18 years old, Patients over 81 years of age, and neuromuscular disease patients who breathe in room air. The data collection sheet had variables such as age, gender, vital signs, NMD Type, Duration of NIV, NIV Parameters, NIV Outcomes, ABG test results,. The data entered in Microsoft Excel sheets and subsequently uploaded into SPSS software. The statistical analysis of the variables carried out using SPSS software. Bar charts used to compare the outcome variable.

\section{RESULT}

After meeting the inclusion and exclusion criteria, a total number of 21 patients got enrolled in this study. Out of the selected subjects, the males were $14(n=14)$, which constitutes $66.70 \%$ and the females were $7(n=7)$, which constitutes $33.30 \%$ as shown in Figure 1. The minimum age of the subjects was 19 years old and the maximum age was 81 years old with a mean age of 45years old $(n=45)$ (Table 1). The predominant neuromuscular condition in this study subjects was Guillian Barrie syndrome (GBS) which was (28.5\%) followed by Myasthenia Gravis (MG) (14.3\%), Duchene muscular dystrophy (9.5\%). Other conditions such as congenital myotrophy, neuropathy, radiculopathy and other types of 


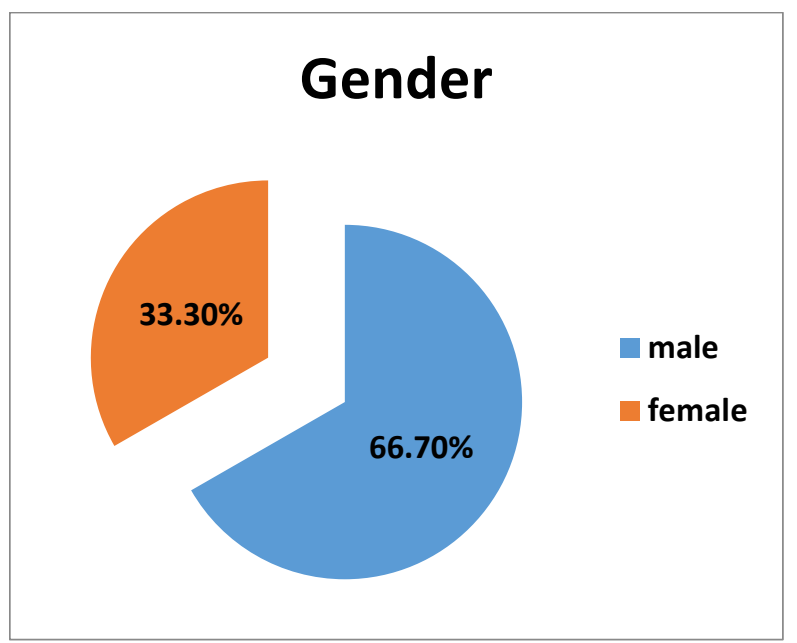

Figure 1: Gender distribution of study subjects

Table 1: Descriptive Statistics on Age

\begin{tabular}{|c|c|c|c|c|c|}
\hline & $\mathbf{N}$ & Minimum & Maximum & Mean & Std. Deviation \\
\hline Age & 21 & 19 & 81 & 45.05 & 20.742 \\
\hline Valid N (list wise) & 21 & & & & \\
\hline
\end{tabular}

\section{Type of Neuromuscular disease}

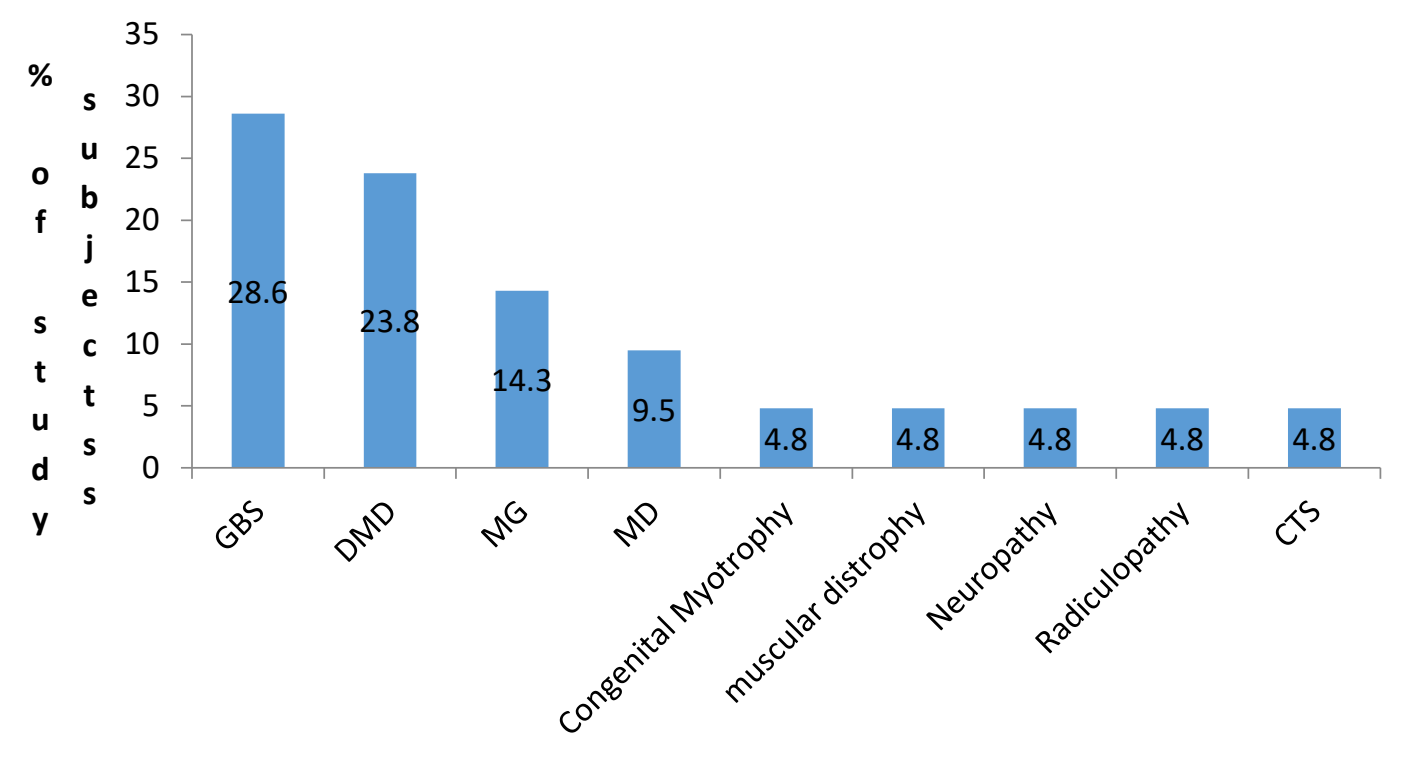

Figure 2: Bar diagram showing the distribution of neuro muscular disease in the study subjects

muscular dystrophies were (4.8\%) as mentioned in Figure 2. All the selected subjects got admitted as inpatients in different Intensive Care Units (ICUs) of King Abdulla Medical City (KAMC) Riyadh.

The subjects in this study were connected with Non Invasive Ventilator (NIV) with oro nasal mask as interface. They were connected with Bi-level Positive Airway Pressure (BIPAP) which has a parameter Inspiratory Positive Airway Pressure (IPAP) and Expiratory Positive Airway Pressure (EPAP). In this study, the minimum duration of NIV was 2 hours and maximum duration was 10 hours 40 minutes with minimum IPAP settings $10 \mathrm{~cm}$ of $\mathrm{H} 2 \mathrm{O}$ and maximum settings of $18 \mathrm{~cm}$ $\mathrm{H} 2 \mathrm{O}$. The minimum Expiratory Positive Airway Pressure (EPAP) was set at $4 \mathrm{cmof} \mathrm{H} 2 \mathrm{O}$ and maximum of $8 \mathrm{~cm}$ of $\mathrm{H} 2 \mathrm{O}$. The minimum duration of NIV with oxygen was 20 minutes were as the maximum was 40 minutes (Table 2). 
Table 2: Mean and Standard Deviation for various parameters

\begin{tabular}{llcccc}
\hline & N & Minimum & Maximum & Mean & Std. Deviation \\
\hline Duration of NIV by hours & 21 & 2 & 624 & 123.67 & 197.985 \\
\hline $\begin{array}{l}\text { NIV Parameters inspiratory positive airway } \\
\text { pressure }\end{array}$ & 21 & 10 & 18 & 13.24 & 2.406 \\
$\begin{array}{l}\text { NIV Parameters expiratory positive airway } \\
\text { pressure }\end{array}$ & 21 & 4 & 8 & 5.95 & 1.322 \\
\hline NIV Parameters oxygen & 21 & .20 & 40.00 & 2.2576 & 8.64867 \\
\hline
\end{tabular}

Table 3: Comparison of pre and post $A B G$ parameters after NIV use

\begin{tabular}{|c|c|c|c|c|c|c|}
\hline & & Mean & $\mathbf{N}$ & Std. Deviation & T value & P value \\
\hline \multirow{2}{*}{ Pair 1} & pre-NIV Ph & 7.3177 & 21 & .07833 & -2.356 & $0.029 *$ \\
\hline & post-NIV Ph & 7.3700 & 21 & .05854 & & \\
\hline \multirow{2}{*}{ Pair 2} & pre-NIV carbon dioxide & 65.0190 & 21 & 23.89597 & 2.269 & $0.034^{*}$ \\
\hline & post-NIV carbon dioxide & 54.9619 & 21 & 13.45126 & & \\
\hline \multirow{2}{*}{ Pair 3} & pre-NIV oxygen & 63.0857 & 21 & 23.15045 & -2.933 & $0.008^{*}$ \\
\hline & post-NIV oxygen & 90.5571 & 21 & 33.90349 & & \\
\hline \multirow{2}{*}{ Pair 4} & pre-NIV HCO3- & 30.7429 & 21 & 8.14976 & 0.649 & 0.524 \\
\hline & post-NIV HCO3- & 29.6762 & 21 & 7.29533 & & \\
\hline
\end{tabular}

Table 4: NIV Outcomes

\begin{tabular}{|c|c|c|c|}
\hline & & Frequency & Percent \\
\hline \multirow{5}{*}{ Valid } & Room air & 3 & 14.3 \\
\hline & shifted to NC & 5 & 23.8 \\
\hline & Intubated & 12 & 57.1 \\
\hline & Tracheotomy & 1 & 4.8 \\
\hline & Total & 21 & 100.0 \\
\hline
\end{tabular}

An Arterial Blood Gas (ABG) analysis was done Pre and Post NIV and was compared using paired ' $t$ ' test. The analyzed and compared $\mathrm{ABG}$ parameters were $\mathrm{pH}$, arterial pressure of carbon dioxide ( $\mathrm{PaCO} 2)$, arterial bicarbonate ( $\left.\mathrm{HCO}^{-}\right)$and pre and post values of partial pressure of arterial Oxygen $\left(\mathrm{PaO}_{2}\right)$. The mean pH pre NIV (7.31) and post NIV (7.37) with a $P$ value ( $p-0.029)$ showed statistical significance. The mean PaCO2 pre NIV $(65.02 \mathrm{mmHg})$ and post NIV (54mmHg) with a $P$ value $(P-0.034)$ and the mean oxygenation pre NIV $(63.9 \mathrm{mmHg})$ and post NIV $(90.55 \mathrm{mmHg})$ with a $P$ value $(P-0.008)$ was also statistically significant as shown in the Table $\mathbf{3}$. There was a slight difference in arterial bicarbonate in pre and post NIV.

The outcome of NIV in this study was not that effective. Out of the total 21 subjects, majority of the subjects ( $n=12$ ) got intubated and mechanically ventilated $(57.1 \%)$, some patients $(n=5)$ was connected to nasal cannula $(23.8 \%)$, while others $(n=3)$ made into room air (14.3\%) and tracheostomised $(n=1)$ (Table 4).

\section{DISCUSSION}

The study was conducted to see the effectiveness of Non-invasive ventilation on the survival and improvement of patients with neuromuscular disease. In this study, we collected data of 21 neuromuscular disease patients all of whom used NIV. The age varies between 18 and 81 with the mean of 56 year-old. We analyzed, retrospectively their data and the outcomes were $57.1 \%$ got intubated, $4.8 \%$ deteriorated and got tracheostomy, $23.8 \%$ got better and shifted to nasal cannula, and $14.3 \%$ were on room air. From this result we can deduct that most patients got their condition worsen and the NIV treatment did not make a major effect. But that can be due to the patient own health. Since sample of patients we have contains a lot of elderly patients and some of whom had co-existing illness. They can develop respiratory failure because of the weak muscles. Most importantly though, this does not mean the NIV therapy will directly be good for young people. However, another study about the outcome of non-invasive positive pressure ventilation in pediatric neuromuscular conducted by The Hospital for Sick Children, Toronto, Canada. [22] Showed that there is notable improvement in children health. The time spent during hospitalizations was significantly lower. [22] Children spent 85\% fewer days in hospital mean pre-NIV 48.0 days, the mean post-NIV 7.0 days. [22] Unfortunately, this does not support our previous clinical impression and reported findings in adult. 


\section{CONCLUSION}

In conclusion, it is hard to say that NIV improve the quality of life in our study. Since most of the results indicates otherwise. But other studies show vast improvement. This can be due to the limitations and biases in the study. The limitations are the heterogeneity of the diseases and the progressive ones. The bias can be due to the hospital and its policies. In the end we think we need more studies to show if there is an association between the progressiveness of neuromuscular disease and improvement of the patient with respiratory problems at the time of using NIV.

\section{REFERENCES}

1. Kacmarek R, Stoller J, Heuer A, Chatburn R, Kallet R. Egan's fundamentals of respiratory care. 11th ed. St. Louis, Missouri 63043: Elsevier. 2013:655-659. PMCid:PMC4056076

2. Simonds AK. Recent Advances in Respiratory Care for Neuromuscular Disease. Chest. 2006;130(6):1879-1886. https://doi.org/10.1378/chest.130.6.1879 PMid:17167012

3. Wokke JHJ, van Doorn PA, Hoogendijk JE, de Visser M, Wokke JHJ, van Doorn PA. Neuromuscular disease. 2nd ed. New York: Cambridge University Press. 2013:95-100.

4. Spitzer AR, Giancarlo T, Maher L, Awerbuch G, Bowles A. Neuromuscular causes of prolonged ventilator dependency. Muscle Nerve. 1992;15(6):682-6. https://doi.org/10.1002/mus.880150609 PMid:1508233

5. Hutchinson D, Whyte K. Neuromuscular disease and respiratory failure. Pract Neurol. 2008;8(4):229-37. https://doi.org/10.1136/pn.2008.152611 PMid:18644909

6. Moritz F, Benichou J, Vanheste M. Boussignac continuous positive airway pressure device in the emergency care of acute cardiogenic pulmonary oedema: a randomized pilot study. Eur J Emerg Med. 2003;10(3):204-8. https://doi.org/10.1097/00063110-200309000-00009 PMid:12972896

7. Rusterholtz T, Kempf J, Berton C, Gayol S. Noninvasive pressure support ventilation with face mask in patients with acute cardiogenic pulmonary edema (ACPE). Intensive Care Med. 1999;25(1):21-8. https://doi.org/10.1007/s001340050782 PMid:10051074

8. Hillberg RE, Johnson DC. Noninvasive ventilation. N Engl J Med. 1997;11;337(24):1746-52.

9. Lisboa, C, Díaza, O, Fadicb R. Noninvasive mechanical ventilation in patients with neuromuscular diseases and in patients with chest restriction. Archivos de Bronconeumología (English Edition). Arch Bronconeumol. 2003;39(7):314-20. https://doi.org/10.1016/S0300-2896(03)75392-7 PMid:12846961

10. Stevens R, Marshall S, Cornblath D, Hoke A, Needham D, de Jonghe B. A framework for diagnosing and classifying intensive care unit-acquired weakness. Crit Care Med. 2009;37(10):299-308. https://doi.org/10.1097/CCM.0b013e3181b6ef67 PMid:20046114

11. Mehta S. Neuromuscular disease causing acute respiratory failure. Respir Care. 2006;51(9):1016-21. PMid:16934165

12. Eagle M, Baudouin SV, Chandler C, Giddings DR. Survival in Duchenne muscular dystrophy: improvements in life expectancy since 1967 and the impact of home nocturnal ventilation. Acta Myol. 2012;31(2):121-125.

13. de Vries J, Hagemans M, Bussmann J, van der Ploeg A, van Doorn P. Fatigue in neuromuscular disorders: focus on Guillain-Barré syndrome and Pompe disease. Cell Mol Life Sci. 2010;67(5):701-713. https://doi.org/10.1007/s00018-009-0184-2 PMid:20196238 PMCid:PMC2824125

14. O. Benditt J, J. Boitano L. Pulmonary Issues in Patients with Chronic Neuromuscular Disease: American Journal of Respiratory and Critical Care Medicine. ATS Journals. 2013;187(10).

15. Baudouin S, Blumenthal S, Cooper B. Non-invasive ventilation in acute respiratory failure. Thorax. 2002;57(3):192211. https://doi.org/10.1136/thorax.57.3.192 PMCid:PMC1746282

16. V Lightowler J, A Wedzicha J, W Elliott M. Papers Non-invasive positive pressure ventilation to treat respiratory failure resulting from pulmonary disease. BMJ. 2003;326(7382):185. https://doi.org/10.1136/bmj.326.7382.185

17. Cabrera Serrano $M$, Rabinstein AA. Causes and outcomes of acute neuromuscular respiratory failure. Arch Neurol. 2010;67(9):1089-1094. https://doi.org/10.1001/archneurol.2010.207 PMid:20837853

18. Radunovic A, Annane D, Jewitt K, Mustfa N.Mechanical ventilation for amyotrophic lateral sclerosis/motor neuron disease. Cochrane Database Syst Rev. 2009;(4).

19. Hutchinson D, Whyte K. Neuromuscular disease and respiratory failure. Pract Neurol. 2008;8(4):229-37. https://doi.org/10.1136/pn.2008.152611 PMid:18644909 
20. Bourke SC, Bullock RE, Williams TL, Shaw PJ, Gibson GJ. Effects of non-invasive ventilation on survival and quality of life in patients with amyotrophic lateral sclerosis: a randomised controlled trial. Lancet Neurol. 2006;5(2):1407. https://doi.org/10.1016/S1474-4422(05)70326-4

21. Ambrosino N, Carpene N, Gherardi M. Chronic respiratory care for neuromuscular diseases in adults. Eur Respir J. 2009;34(2):444-51. https://doi.org/10.1183/09031936.00182208 PMid:19648521

22. Katz S, Selvadurai H, Keilty K, Mitchell M, MacLusky I. Outcome of non-invasive positive pressure ventilation in paediatric neuromuscular disease. Archives of Disease in Childhood. 2004;89(2):121-124. https://doi.org/10.1136/adc.2002.018655

APPENDICES

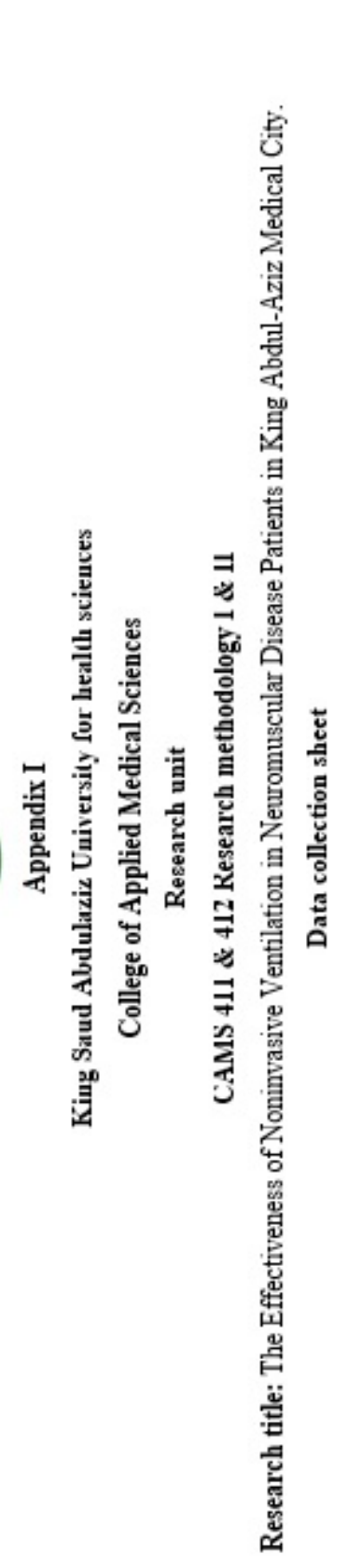

Data collection format

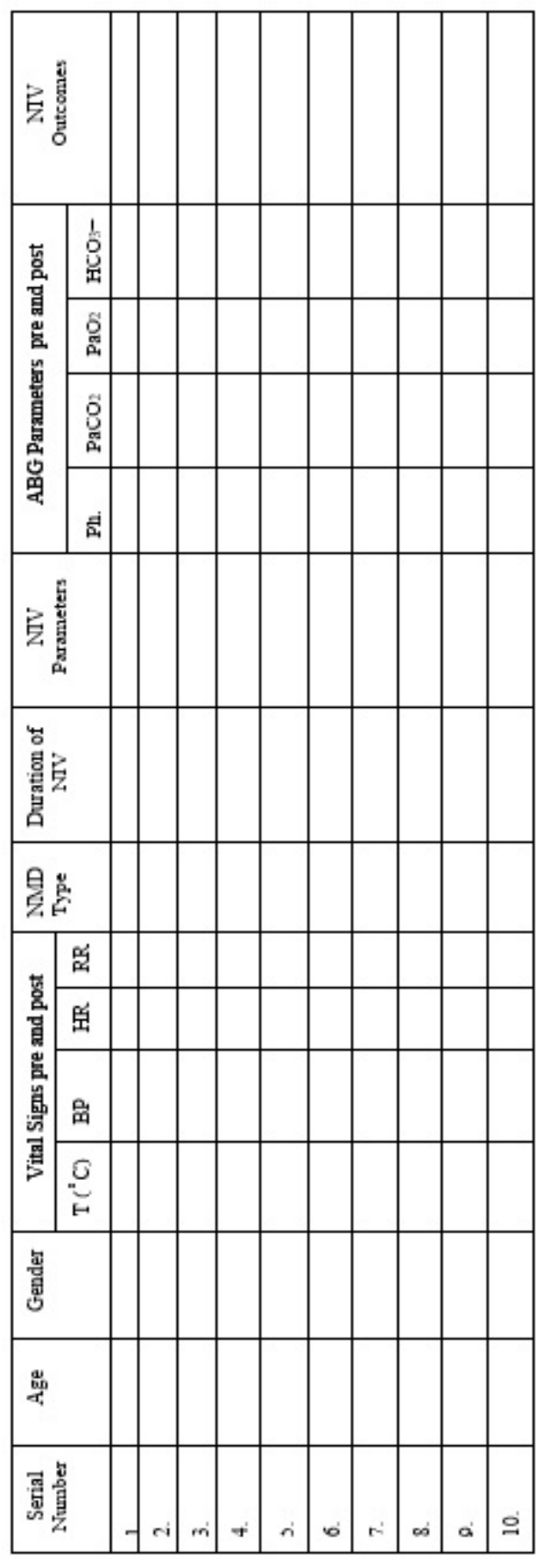

